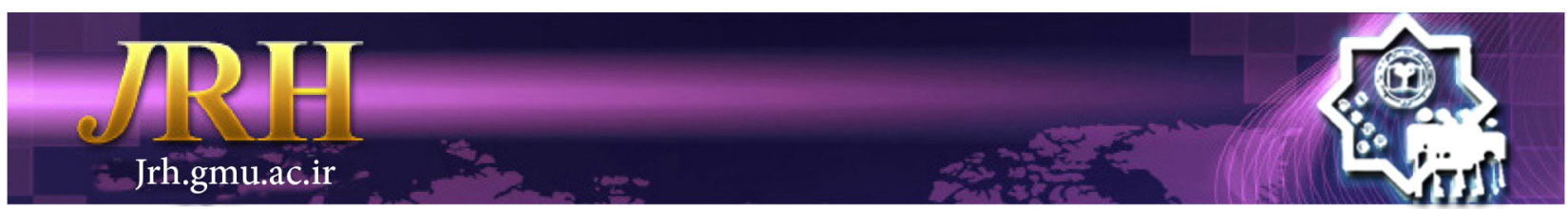

\title{
Urinary tract infection preventive behaviors among adolescent girls: a quasi-experimental study
}

Naval Heydari ${ }^{1}$, Iran Jahanbin ${ }^{2}$, Fariba Ghodsbin ${ }^{3}$

\author{
Journal of Research \& Health \\ Social Development \& Health Promotion \\ Research Center \\ Vol. 9, No.4, Jul \& Agu 2019 \\ Pages: $330-336$ \\ DOI: $10.29252 /$ jrh. 9.4 .330 \\ Original Article
}

1. Student Research Committee; Department of Nursing, School of Nursing and Midwifery; Shoushtari Mother and Child Hospital, Shiraz University of Medical Sciences,Shiraz, Iran

2. Department of Community Health Nursing, School of Nursing and Midwifery, Shiraz University of Medical Sciences, Shiraz, Iran

3. Correspondence to: Geriatric Research Center; Department of Community Health Nursing, School of Nursing and Midwifery, Shiraz University of Medical Sciences, Shiraz, Iran

Email: ghodsbin93@gmail.com

Received: 14 Jun 2016

Accepted: 10 Oct 2016

How to cite this article: Heydari N, Jahanbin I, Ghodsbin F. Urinary tract infection preventive behaviors among adolescent girls: a quasi-experimental study. $J$ Research \& Health2019; 9(4): 330- 336.

\begin{abstract}
Based on the 40 to $50 \%$ prevalence of urinary tract infection in women and the role of education in changing health behaviors, this study was conducted aiming to determine the role of education on preventive behaviors of urinary tract infection in female adolescents. This quasi-experimental study was conducted on 168 high school female adolescents; they were selected using cluster and simple sampling methods. The effect of education was examined by using a valid and reliable questionnaire which had been designed by the researcher. The intervention consisted of six-hour training classes over 4 sessions for the teens. Before the intervention, neither control nor intervention groups had differences in 4 domains of behavioral score and total score, but after the intervention, the mean scores in all areas were significantly increased. Considering the positive impact of education on health behaviors of adolescents, the use of this method is useful to change their behaviors in the prevention of urinary tract infection.
\end{abstract}

Keywords: Female Adolescents, Health Behavior, Urinary Tract Infection

\section{Introduction}

Urinary tract infection is one of the most common bacterial infections which affects about $20 \%$ of women between 20 and 65 years old. The frequency of acute cystitis is 0.5 to 0.7 in every person per year and about 40 to $50 \%$ of women are affected at least once by urinary tract infections in their life [1]. The incidence of bacteriuria has almost remained stable in the ages of 6 to 15. But in adolescent girls, the incidence of urinary tract infections has reached $20 \%$, while in young boys it has remained constant [2]. It is estimated that 5 to $6 \%$ of girls will experience at least a bacteriuria throughout their school years $[3,4]$. According to Ahmed et al, urinary tract infection prevalence in the 10 to 19 year old girls was $12.7 \%$ in India [5]. From almost every 10 girls, 1 person and from every 30 boys, 1 person will be affected with urinary tract infections up to 16 years old [6]. According to studies conducted in Iran in Mazandaran province, the prevalence of urinary tract infection in men and women was $1.73 \%$ and $14.9 \%$, respectively. Results of another study in the same year in Isfahan showed $82 \%$ of patients were women (mostly young) and 18\% were men [4]. The recurrence probability is another issue that associates with this disease. Around 13 to 25 
percent of the affected population are women with multiple re-infection [7]. Moreover, the economic burden of urinary tract infection that is annually 150 million people worldwide suffering, and health care cost that is at least 6 million dollars make it necessary to increase attention to this disease $[2,4,8]$.

Individual health behaviors such as those related to sexual activity, kind of underwear, how often the underwear is replaced, kind of nutrition, how to wash after urination and defecation, postponing urination, past history of urinary tract infection, and infections during early ages and before age 15 are the factors that raise a person's susceptibility to this disease [3, 9-13]. Therefore, proper health behaviors can prevent the development of the disease. [8] Health education can change behavior and inclusive multiple methods [13]. Health education will encourage and empower people to accept and perform voluntary healthy behaviors [14]. It is a convenient tool for all nurses for helping patients and families to obtain the beneficial health behaviors and to change risky lifestyles in terms of health [13]. On the other hand, the community health nurses in health education have a particular and important position due to their relationship with clients in different environments with diverse abilities and needs [15]. Thus, due to the importance of adolescent hood [16], counting female adolescents as a significant portion of the country's population, the high prevalence of urinary tract infection among them, and association of this disease with individual health behaviors, the researchers were prompted to take actions in this regard based on primary prevention, which is a role of community health nurse. Therefore, this study aims to determine the effect of education on preventive behaviors of urinary tract infection in female adolescents. Therefore, this study aims to determine the effect of education on preventive behaviors of urinary tract infection in female adolescents.

\section{Method}

This is a quasi-experimental study conducted in 2014 in Shiraz (Iran). The participants in this study were 168 grade one high school teenager girls. The sample size was calculated using the sample size formula in the Power and Sample Size Software (PASS), taking into account the error of $5 \%, 80 \%$ power and effect size of $40 \%$ and finally with $20 \%$ downfall, 84 participants in both control and intervention groups.

The data gathering tool in this study was a researcher-made questionnaire based on health belief model according to previous studies [8,11], which contains two parts: demographic information part that contains 6 questions and evaluating prevention behaviors of urinary tract infection. This section has 18 questions and includes nutritional behaviors (4 questions), individual health behaviors (6 questions), health behaviors of clothing (6 questions) and behavior related to urination (2 items). Scoring the questions was based on Likert scale ranging from 1 to 5 for each question and accordingly the total score range of behavior was variable from 18 to 90 . Content and nominal validity of the questionnaire was confirmed according to five experts' opinions and its reliability was determined 0.73 using Cronbach's Alpha.

Cluster sampling method was used in this research; 2 areas of four education areas were selected at first and then two schools were selected randomly from each area and were considered as intervention and controls samples and 42 people from each school were selected purposefully (Figure 1). Inclusion criteria were, students educating at the first year of high school and providing written consent to participate in the study. Exclusion criteria included having a history of education on urinary tract infections, being absent more than one session.

At first, a pretest was performed for all samples and then the intervention group participated in a 6 hour training course during 4 sessions. The method of education was as follows: at first, the researcher educated 12 persons of the intervention group selected based on having the sense of responsibility and ability to 
transfer the contents according to the declaration of their school's officials. The education was done through lecturing and distribution of educational booklets summarizing information about Urinary Tract Infection (UTI). Then, they educated their classmates in 2 one-hour sessions through discussions in small groups and providing booklets. A month after the intervention, a posttest was performed for both intervention and control groups. No intervention was done for the control group and after the end of the intervention in the experimental group, a training booklet was also available to the control group to protect the research ethics. At the end, the data were analyzed using descriptive statistics, paired t-test and t-independent test (significance level at $<0.05$ ).

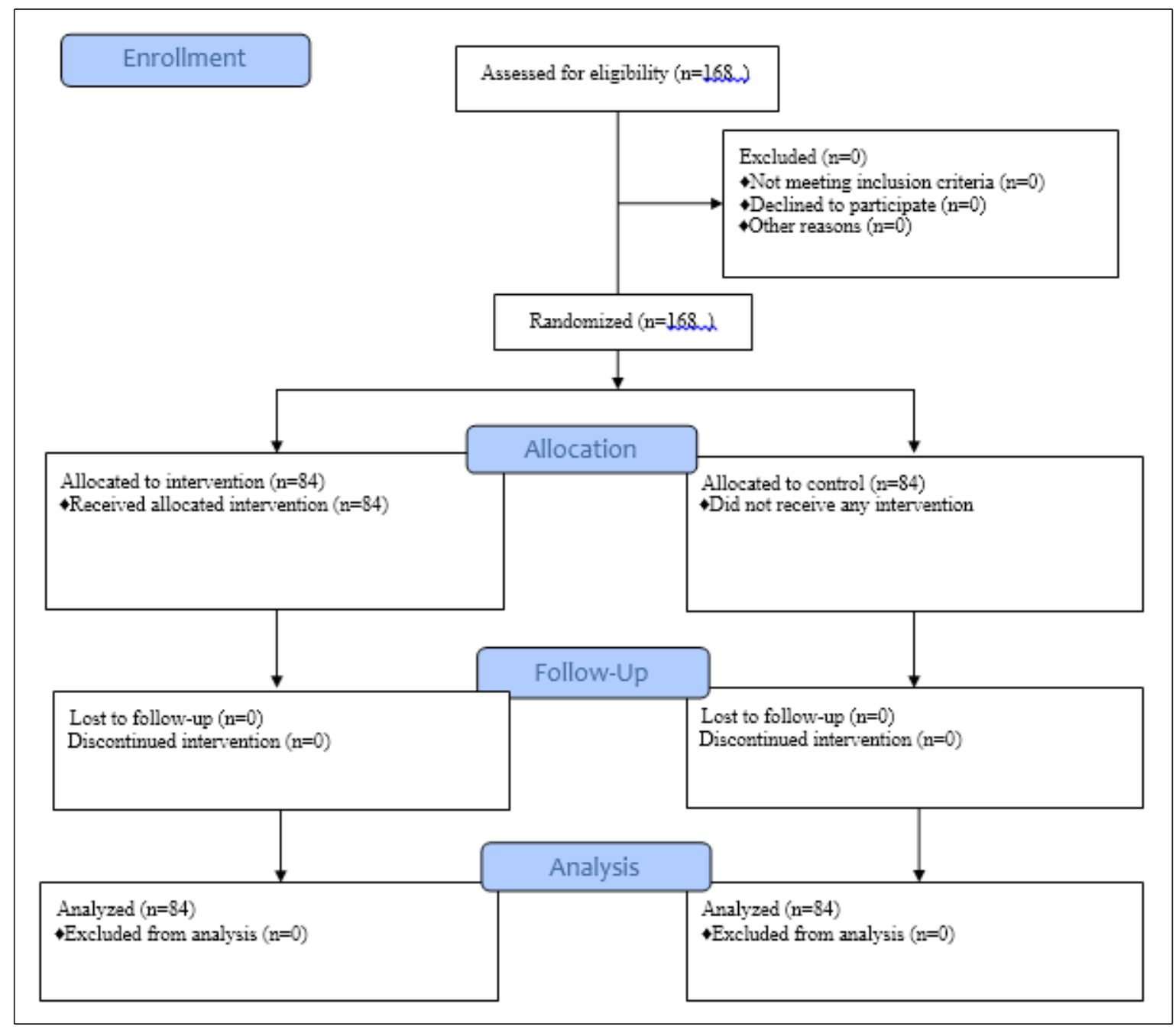

Figure 1 Flow diagram of the participants during the study

\section{Results}

In this study, there was no loss of sample size. According to independent t-test result, there was no significant difference between both control and intervention groups in terms of age, father's occupation, and mother's job ( $\mathrm{p}>0.05)$. However, the level of parents' education was significantly different between them $(p<0.05)$. The majority of their fathers were selfemployed and their mothers were housewives.
As to the education level, fathers had high school diploma and the majority of mothers in the intervention group had high school diploma; most of those in the control group had lower secondary education. The mean age of the adolescents was $15.7 \pm 0.6$.

According to independent t-test result, the mean scores for preventive behaviors of urinary tract infection before the intervention 
in both intervention and control groups showed no difference with each other $(\mathrm{p}>0.05)$ (Table 1). Nevertheless, after the intervention, mean scores in all aspects of behavior in the intervention group was significantly increased $(p<0.05)$. While in the control group, the mean scores in all dimensions, except for personal health behaviors, increased; only in terms of hygienic behaviors of wear, it was meaningful $(\mathrm{p}<0.043)$ (Tables 1, 2).

Table 1 Comparison of preventive behaviors of urinary tract infection mean scores in both intervention and control groups before and after the intervention

\begin{tabular}{lllclc}
\hline \multicolumn{1}{c}{$\begin{array}{c}\text { Preventive behaviors of urinary } \\
\text { tract infection }\end{array}$} & $\begin{array}{c}\text { Before } \\
\text { intervention }\end{array}$ & p-value & $\begin{array}{c}\text { After } \\
\text { intervention }\end{array}$ & p-value \\
\hline Feeding behavior & $\begin{array}{l}\text { Intervention } \\
\text { Control }\end{array}$ & $\begin{array}{c}13.86 \pm 2.83 \\
13.65 \pm 2.79\end{array}$ & 0.623 & $15.38 \pm 2.28$ & $<0.001$ \\
\hline $\begin{array}{l}\text { Individual health } \\
\text { behaviors }\end{array}$ & Intervention & $23.59 \pm 3.86$ & 0.561 & $26.04 \pm 3.13$ & $<0.001$ \\
\hline $\begin{array}{l}\text { Clothing Health } \\
\text { behaviors }\end{array}$ & Control & $23.96 \pm 4.32$ & & $23.25 \pm 4.63$ & \\
\hline \multirow{2}{*}{$\begin{array}{l}\text { Intervention } \\
\text { Crination Behavior }\end{array}$} & $20.33 \pm 4.65$ & & $22.92 \pm 4.46$ & $<0.040$ \\
\hline Total & Control & $20.53 \pm 5.69$ & 0.801 & $21.41 \pm 4.98$ & \\
Score & Intervention & $7.15 \pm 1.91$ & 0.081 & $8.82 \pm 1.33$ & $<0.001$ \\
\hline
\end{tabular}

*Independent t-test was used.

Table 2 Comparison of preventive behaviors of urinary tract infection mean scores in the intervention and control groups

\begin{tabular}{llcc}
\hline Group & The mean and & p-value \\
\hline & Total score of behavior & $8.22 \pm 7.86$ & $<0.001$ \\
& Feeding behavior & $1.51 \pm 3.01$ & $<0.001$ \\
Intervention & Individual health behaviors & $2.45 \pm 3.38$ & $<0.001$ \\
& clothing Health behaviors & $2.59 \pm 4.29$ & $<0.001$ \\
& Urination Behavior & $1.66 \pm 1.78$ & $<0.001$ \\
\hline Total score of behavior & $.34 \pm 8.60$ & 0.714 \\
& Feeding behavior & $.09 \pm 2.62$ & 0.741 \\
Individual health behaviors & $-.71 \pm 3.74$ & 0.084 \\
& clothing Health behaviors & $.88 \pm 3.93$ & 0.043 \\
& Urination Behavior & $.08 \pm 2.09$ & 0.716 \\
\hline
\end{tabular}

*Paired t-test was used.

\section{Discussion}

The results showed a significant increase in the intervention group's behavior compared to the control group; this is similar to the results of Javaheri Tehrani's study on married women [11]. In that study, mean scores of feeding behaviors, personal health behaviors, clothing health behaviors and urination behavior significantly increased and had compliance with results of Taghdisi's study [17] on pregnant women and
Hashemiparast's study [8] on the mothers of children under 6 years. As to the impact of education on preventive behaviors of urinary tract infection, the results of this study was in line with those of the present study. Kanicka et al. [18] and Sharifirad et al.'s studies [19] in the field of tobacco use and smoking in students also reflected the positive impact of health education on the students' behavior. 
Other studies are also consistent with the current one; for example, Motamedi et al.'s study [14] aimed at determining the effect of education based on health belief model on promoting preventive behavior of leishmaniasis; the score of taking action before and after training showed a significant difference.

The positive impact of education on the mean score of behavior was confirmed in Lotfi et al,'s study [20] in the field of feeding behavior of students, and Baghiyani et al.'s study [21] on walking in diabetic patients. Moreover, another study in Mashhad (Iran) showed the positive effect of health education on physical activity in diabetic women [22] and similar to this investigation, another study in China showed that health education can improve the feeding behavior in diabetic patients [23]. Of other foreign studies that have been conducted on the effect of education on behavior is a study in Finland that aimed at determining the effect of education on knowledge and health behaviors related to osteoporosis in patients with this disease; also in this study, education was effective on dietary preventive behaviors of osteoporosis [24]. In a survey in America on the health education about asthma, a great impact was found on self-care behaviors of students suffering from this disease [25]. Also, in Turkey, a study about the effect of education about blood pressure control strategies on healthy behaviors about healthy lifestyle showed the important role of nurses in improving the subjects' healthy behaviors [26] Thus, based on various studies, nurses can have an important role in changing behavior and individuals' health promotion by health education. Due to the limitations of this study including lack of opportunity to work with students because of the collision with their examinations and classes, further studies in this field are recommended using different and modern educational methods and utilization of nursing and health education theories while considering time limitation for working with students.

\section{Conclusion}

Results of this study confirmed the positive impact of health education on nutritional behaviors preventing the urinary tract infection, personal health, clothing hygiene and urinating in girls. Therefore, due to the high incidence of urinary tract infection in adolescent girls and the positive impact of such interventions, the needs to hold training in schools or social gathering places of female adolescents is emphasized to change their health behaviors.

\section{Acknowledgments}

This article is extracted from the master's thesis of Naval Heydari with the clinical trial registration code of IRCT201404167531N5 and the Ethics Committee of Shiraz University of Medical Sciences approval number of CT-92-6926. The researchers would like to thank and appreciate the Vice Chancellor of Research in the University of Medical Sciences and Department of Education in Shiraz for their support and cooperation. The authors would also like to thank Shiraz University of Medical Sciences, Shiraz, Iran as well as Center for Development of Clinical Research of Nemazee Hospital and Dr. Nasrin Shokrpour for editorial assistance

\section{Authors' contributions}

Study design: NH, IJ, FGh

Data collection and analysis: $\mathrm{NH}$

Manuscript preparation: NH, IJ, FGh

All authors have read and approved the final version.

\section{Conflict of Interest}

"The authors declare that they have no competing interests."

\section{Funding}

The author (s) received financial support for the research from the Vice Chancellor of Research in Shiraz University of Medical Sciences, Shiraz, Iran with research number: 92-6926.

\section{Availability of data and materials}

The datasets used and/or analyzed during this 
study are available from the corresponding author on reasonable request.

\section{References}

1- Franco AVM. Recurrent urinary tract infections. Best Pract Res Clin Obstet Gynaecol2005; 19(6): 861-73.

2- McAninch JW, Lue TF. Smith \& tanagho's general urology. New York: Lange Medical Books/McGrawHill; 2012.

3- Hockenberry MJ, Wilson D. Wong's nursing care of infants and children . 10th ed. Mosby, US: Elsevier Health Sciences; 2014.

4- Tabrizian L, Nikpour S, Masroor-Roodsari D, Haghani H. Individual predisposing factors to urinary tract infection (UTI) in married women. Iran Journal of Nursing2003; 16(35): $20-4$.

5- Ahmed SM, Avasarala AK. Urinary tract infections (UTI) among adolescent girls in rural Karimnagar District, AP- K.A.P Study. Indian J Pre Soc Med2009; 40(1-2): 6-9.

6- Baghiani-Moghadam MH, Shojaeazadeh D, Mohamadloo A, Fallahzadeh H, Ranjbary M. Evaluation of preventive behaviors of UTI based on health belief model (HBM) in mothers with girls younger than 6 years old. Toloo-e-Behdasht2013; 12 (1): 78-88.

7- Wein AJ, Kavoussi LR, Novick AC, Partin AW, Peters CA. Campbell-walsh urology. Volume 4. 10th ed. Philadelphia, US: Saunders; 2011.

8- Hashemi-Parast M, Shojaizade D, Dehdari T, Gohari MR. Design and evaluation of educational interventions on the health belief model to promote preventive behaviors of urinary tract infection in mothers with children less than 6 years. Razi Journal of Medical Sciences 2013; 20(110): 22-8.

9- Haji-Amini Z, Rajaei M, Razaghi M, et al. Prevalence and predisposing factors of urinary tract infection in girl students. Kowsar Medical Journal2006; 11(1): 91-9.

10- Hooton TM. Recurrent urinary tract infection in women. Int J Antimicrob Agents2001; 17(4): 259-68.

11- Javaheri-Tehrani F, Nikpour S. Effect of an educational program based on the health belief model on preventive behaviors of urinary tract infection among women. Preventive Care in Nursing \& Midwifery Journal2013; 3(1): 1-11.

12- Nasiri-Amiri F, Hasanjani-Roshan MR, HajiAhmadi M, Akbarzade-Pasha Z. The role of hygienic behavior on incidence of urinary tract infection among pregnant women reffered to health center, Babol, 20022004. Journal Babol University Medical Sciences2006; 8(2): 56-62.

13- Brunner LS, Smeltzer SC, Bare BG, Hinkle JL, Cheever KH. Brunner and Suddarth's textbook of medical - surgical nursing. 12th ed. Philadelphia, US:
Wolter Kluwer /Lippincott Wlliams and Willkins; 2010.

14- Motamedi N, Hejazi SH, Hazavei SMM, Zamani AR, Saberi S, Rahimi E. Effect of education based on health belief model on promoting preventive behavior of coetaneous leishmaniasis. Journal of Military Medicine 2010; 11(4): 231-6.

15- Stanhope M, Lancaster J. Foundations of community health nursing: community-oriented practice. Maryland Heights, Missouri, US: Mosby; 2001.

16- Taghdisi MH, Noori-Sistani M, Merghati-Khoi E, Hoseini F, Asgharnejad-Faid AA. Impact peer education approach on knowledge and practice about mental health of adolescent girls. Toloo-eBehdasht2011; 10(3-4): 92-105.

17- Taghdisi MH, Nejadsadeghi E. Evaluation of knowledge, attitude and health behaviour of the pregnant women consulted in Behbahan health centers in the field of urinary infections based on the health belief model (HBM) (2010). Modern Care Journal2011; 8(3): 143-51.

18- Kanicka M, Poniatowski B, Szpak A, Owoc A. Differences in the effects of anti-tobacco health education programme in the areas of knowledge, attitude and behaviour, with respect to nicotinism among boys and girls. Ann Agric Environ Med2013; 20(1): 173-7.

19- Sharifi-Rad Gh, Hazavei MM, Hasan-Zadeh A, Danesh-Amouz A. The effect of health education based on health belief model on preventive actions of smoking in grade one, middle school students. Arak Medical University Journal2007; 10(1): 79-86.

20- Lotfi-Mainbolagh B, Rakhshani F, Zareban I, Montazerifar F, Alizadeh-Sivaki H, Parvizi Z. The effect of peer education based on health belief model on nutrition behaviors in primaryschool boys. Journal of Research \& Health2012; 2(2): 214-25.

21- Baghiani-Moghadam MH, Hadavandkhani M, Mohammadi M, Fallahzade H, Baghiani-Moghadam B. Current education versus peer-education on walking in type 2 diabetic patients based on health belief model: A randomized control trial study. Rom J Intern Med2012; 50(2): 165-72.

22- Mahdizadeh MS, Peymam N, Taghipour A, Esmaily $\mathrm{H}$, Mahdizadeh SM. Effect of health education program on promoting physical activity among diabetic women in Mashhad, Iran: Applying Social Cognitive Theory. Journal of Research in Health Sciences2013; 13(1): 90-7.

23- Wang H, Song Z, Ba Y, Zhu L, Wen Y. Nutritional and eating education improves knowledge and practice of patients with type 2 diabetes concerning dietary intake and blood glucose control in an outlying city of 
China. Public Health Nutr2014; 17(10): 2351-8.

24- Laslett LL, Lynch J, Sullivan TR, McNEIL

JD. Osteoporosis education improves osteoporosis knowledge and dietary calcium: Comparison of a 4 week and a one-session education course. Int J Rheum Dis2011; 14(3): 239-47.

25- Kintner EK, Cook G, Marti CN, et al. Effectiveness of a school and community-based academic asthma health education program on use of effective asthma self-care behaviors in older school-age students. $J$ Spec Pediatr Nurs2015; 20(1): 62-75.

26- Hacihasanoğlu R, Gözüm S. The effect of patient education and home monitoring on medication compliance, hypertension management, healthy lifestyle behaviours and BMI in a primary health care setting. J Clin Nurs2011; 20(5,6): 692-705.

Copyright $@ 2016$ ASP Ins. This open-access article is published under the terms of the Creative Commons Attribution-NonCommercial 4.0 International License which permits Share (copy and redistribute the material in any medium or format) and Adapt (remix, transform, and build upon the material) under the Attribution-NonCommercial terms. 